\title{
Política Ambiental: a negligência do urbano na Amazônia
}

\author{
Marco Antonio Chagas ${ }^{1}$, Jennyfer Sabriny Araujo Santos ${ }^{2}$ e \\ Edilene Lira da Silva ${ }^{3}$
}

\footnotetext{
1 Doutor em Desenvolvimento Socioambiental pelo Núcleo de Altos Estudos Amazônicos/UFPA. Professor do Departamento de Meio Ambiente e Desenvolvimento da Universidade Federal do Amapá, Brasil. E-mail: marco.chagas@uol.com.br 2 Acadêmica do Curso de Arquitetura e Urbanismo da Universidade Federal do Amapá, .E-mail: jeennyaraujo@hotmail.com 3 Acadêmica do Curso de Arquitetura e Urbanismo da Universidade Federal do Amapá. E-mail: edilenelira.arq@gmail.com
}

RESUM 0: A Amazônia abriga 25 milhões de habitantes vivendo em meio a uma floresta preservada pela política ambiental hegemônica que incide sobre a região. A urbanização da Amazônia é um fenômeno das últimas três décadas, com casos de estados que atingem 99,3\% da população concentrada em núcleos urbanos, como o Amapá. Tal fenômeno tem impactado a condição de vida nas cidades, sobretudo na capital do estado, Macapá, onde praticamente não existe cobertura de rede de esgotamento sanitário, além de apresentar baixos percentuais de acesso à água tratada e de manejo de resíduos sólidos. Macapá é a porta de entrada de um dos maiores maciços florestais preservados do planeta. A conexão entre a política ambiental e a politica urbana é um tema que tem pautado debates na busca de elementos teóricos que possam instruir a formulação de política ambiental integrada às questões urbanas. 0 presente artigo traz contribuições a esse debate, sustentando que a política urbana foi negligenciada pelos governos, deixando um campo de dúvidas e incertezas sobre a relação de integração e de benefício mútuo entre a condição de vida urbana e a preservação da floresta.

Palavras-Chave: Amazônia; Política Ambiental; Política Urbana; Saneamento Básico.

\section{Environmental Policy: the neglect of the urban aspect in Amazonia}

ABSTRACT: The Amazon is roof from 25 milion of people living in the middle of a forest preserved by the hegemonic environmental policy that focuses on the region. The urbanization from Amazon it's a phenomenon of three last decades, with cases of states that reach $99,3 \%$ of the concentrated population in the urban cores, like state of Amapá. This phenomenon has been impacted the life conditions in the cities, mainly in the state capital, Macapá, where basically don't exist sanitary sewerage system coverage, beyond to presenting low percentages of clean water access and solid waste management. Macapá is the gateway to one of the largest forest stands preserved of the planet. The connection between environmental policy and urban policy it's a theme that has guided discussions to search for theoretical elements that can instruct the formulation of integrated environmental policy to urban issues. This article bring contributions to this debate, arguing that urban policy has been neglected by governments, leaving a doubt countryside and uncertainties around the integration relationship and mutual benefit between the urban life condition and the forest preservation.

Keywords: Amazon; Environmental Policy; Urban Policy; Basic Sanitation.

\section{INTRODUÇÃO}

Uma das lacunas da política ambiental diz respeito às particularidades dos proble- 
mas urbanos na Amazônia. Via de regra, sua existência é negligenciada pelos mitos que percebem a região como um espaço verde vazio, habitado por populações indígenas e ribeirinhas ou fronteira agropecuária. No entanto, a Amazônia possui uma população de 25 milhões de habitantes, dos quais $72,6 \%$ concentrados em núcleos urbanos. Esses dados revelam a força da questão urbana e fortalece a tese de que a Amazônia é uma floresta urbanizada ${ }^{1}$ a ser protegida, mas também a ser humanizada.

A política ambiental na Amazônia, pelo distanciamento dos problemas urbanos, opera diante de certo descrédito quanto a demonstrar que a qualidade de vida urbana mantém relações conexas com a floresta em pé. Especula-se que ao concentrar população em núcleos urbanos diminui-se o impacto sobre a floresta. Ou, a espacialização da população cria demandas de conexões de infraestrutura que impactam a floresta.

Nesse ínterim, a Amazônia tem sido impactada por intervenções que pouco considera a identidade humana da população e a vulnerabilidade e resiliência dos processos ecológicos da floresta que a abriga.

Entre os problemas urbanos o de maior impacto sobre a região é a falta de saneamento, com cidades apresentando total ausência de cobertura de rede de esgotamento sanitário, além de baixos percentuais de acesso a água tratada e de manejo de resíduos sólidos. Essa situação é insustentável, pois a rica floresta abriga cidades com populações que agonizam.

A perspectiva de aproximação da política ambiental dos problemas urbanos é recente na Amazônia. Para exemplificar, o saneamento básico, um direito constitucional, passou a ser disciplinado no Brasil somente em 2007 com a promulgação da Lei Federal n-11.445/2007, incluindo a obrigação dos municípios elaborarem seus Planos Municipais de Saneamento Básico.

Mas, existe relação entre os problemas urbanos e a condição da floresta capaz de sustentar uma política ambiental integrada para a Amazônia, ou ainda uma teoria capaz de instruir sua formulação?

0 presente artigo discute a falta de integração entre a política ambiental e a política urbana na Amazônia, com ênfase no problema da ausência de saneamento básico, adotando o estado do Amapá como estudo de caso. Argumenta-se que, em que pese o acelerado processo de urbanização da região, a política urbana foi negligenciada pelos governos, deixando um campo de dúvidas e incertezas sobre a relação de integração e de benefício mútuo entre a condição de vida urbana e a preservação da floresta.

\footnotetext{
${ }^{1}$ Termo cunhado pela pesquisadora Bertha Becker em "Desfazendo Mitos: Amazônia, uma floresta urbanizada", texto publicado em 1995 pela UNESCO e empregado em outros estudos da autora com o objetivo de inserir a questão urbana na Amazônia como pauta da geopolítica nacional, incluindo as implicações para a conservação da floresta.
} 
Para investigar o problema exposto é apresentada uma sequencia evolutiva da política ambiental e dos instrumentos de planejamento urbanos e de saneamento básico. Em seguida são caracterizados os fenômenos da urbanização do Amapá e da preservação da floresta, além de verificação da possível relação entre as políticas ambiental e urbana.

\section{A EVOLUÇÃO DA POLÍTICA AM BIENTAL E A QUESTÃO URBANA}

O Brasil deu inicio tardiamente a formulação de sua política ambiental. Enquanto vários países motivados pelos estudos sobre impactos e ameaças ao meio ambiente, de Carson (1962) ao Clube de Roma (1969); pelos desdobramentos da Conferência das Nações Unidas sobre M eio Ambiente Humano realizada em 1972, em Estocolmo/Suécia, formularam suas políticas ambientais na década de 1970, o Brasil somente concebeu sua política em 1981, com a publicação da lei 6.938, que vigora até hoje.

A Lei $6.938 / 81$ se propôs a compatibilizar o desenvolvimento com a proteção do meio ambiente, indicando os principais instrumentos de operacionalização da política ambiental. Tais instrumentos tem forte apelo no controle da poluição e na conservação da natureza, incluindo um instrumento específico para a criação de espaços legalmente protegidos, regulamentado pela Lei 9.985/2000, que instituiu o Sistema Nacional de Unidades de Conservação (SNUC).

Na Conferência das Nações Unidas para o Meio Ambiente e Desenvolvimento (CNUM AD) realizada pela ONU em 1992, na cidade do Rio de Janeiro, a questão urbana foi pautada diante da constatação de que a concentração populacional nos assentamentos urbanos dos países em desenvolvimento exerce forte pressão sobre 0 meio ambiente. A Agenda 21 tornou-se o principal instrumento a recepcionar os problemas ambientais urbanos, mas distantes de uma efetiva proposição de política ambiental urbana capaz de lidar com os problemas enfrentados pelas cidades.

No escopo da política ambiental hegemônica da Agenda Verde, o Programa Piloto para a Proteção das Florestas Tropicais do Brasil (PPG7), em curso na década de 1990, abriu uma frente de estudos voltados para um melhor entendimento das questões urbanas e a preservação da floresta amazônica. Datam dessa época importantes trabalhos publicados com apoio do PPG7, como os de Sawyer e Schuwartzman (1997) e de Becker (1999).

A partir dos anos 2000 , os problemas urbanos passaram a receber maior atenção governamental com a aprovação do Estatuto das Cidades (Lei no 10.257/2001) e a criação de um ministério específico para a pasta em 2003. Entretanto, manteve-se 0 mesmo quadro de falta de integração das políticas públicas, com ações segmentadas em torno de um milagroso Plano Diretor obrigatório para cidades com mais de 20 mil habitantes.

A Conferência das Nações Unidas sobre Desenvolvimento Sustentável, a Rio+20, realizada em 2012, também na cidade do Rio de Janeiro, reconheceu que os proble- 
mas urbanos atuais são os maiores desafios do século XXI. A Rio+20 enfatizou o compromisso com a sustentabilidade das cidades, mediante a garantia do direito ao saneamento ambiental, entre outros.

A política ambiental global tem pautado o tema "cidade sustentáveis". Entretanto, a escala da sustentabilidade apresenta situações bastante diferenciadas entre as cidades, para as quais os instrumentos transitam diante da necessidade de um ordenamento básico a um audacioso projeto de modernidade urbana.

\section{INSTRUM ENTOS DA POLITICA AM BIENTAL E URBANA}

O Zoneamento Ambiental ou Zoneamento Ecológico-Econômico (ZEE) é um dos instrumentos da Política Nacional de M eio Ambiente (PNM A) também previsto como etapa de elaboração do Plano Diretor. No caso das cidades da Amazônia, o ZEE tem o potencial de conectar 0 urbano à floresta, pois traz em sua base conceitual o propósito do planejamento e da gestão territorial em diferentes escalas - urbana, municipal e estadual.

O Plano Diretor é o principal instrumento da política urbana. Entretanto, a dimensão dos problemas acumulados pelas cidades depositou sobre 0 instrumento responsabilidades para além de sua competência. Não obstante, resgatam-se as críticas que Vilaça (2005), citando Singer (1995), faz aos Planos Diretores:

...sem aqui discutir seus aspectos metodológicos e operacionais - é a que diz respeito à amplitude de seus propósitos para uma realidade complexa e mutante que é a realidade urbana da atualidade, os planos diretores fracassaram não só em São Paulo, mas em todo o Brasil e na América Latina. Fracassaram não só porque eram falhos, mas porque tomaram os desejos pela realidade (VILAÇA, 2005).

Complementa Vilaça $(2015$, p. 15) que nenhuma grande realização das maiores cidades do País tem sido creditada ao Plano Diretor, sendo puramente decisão de planejamento imediatista de governos, citando exemplos de São Paulo, Porto Alegre, Belo Horizonte, Belém, Recife, Blumenau, Londrina, Santo André, Goiânia, Ribeirão Preto, Aracaju, Piracicaba, Patotas, etc.

No caso do estado do Amapá, Tostes (2006) tem relatado o distanciamento entre a prática do planejamento participativo e o culto ao "fazejamento" ${ }^{2}$ dos sucessivos Planos Diretores elaborados para os municípios, em particular da capital, Macapá.

Em sua dimensão aplicada ao equacionamento dos problemas urbanos mais graves, o Plano Diretor não dialoga com os recentes Planos M unicipais de Saneamento Básico (PMSB), concebidos como um dos instrumentos da Política de Saneamento

2 "Fazejamento" é uma analogia usada por Tostes $(2014,2015)$ para apontar os descaminhos do planejamento urbano na Amazônia, em particular dos municípios do estado do Amapá, semelhantes em muitos pontos a crítica de Vilaça (2015) aos Planos Diretores. 
Básico do município. O PMSB tem, por sua vez, objetivos que visam possibilitar a criação de mecanismos de gestão pública da infraestrutura do município relacionada aos quatro eixos do saneamento básico, a saber: abastecimento de água; esgotamento sanitário; manejo de resíduos sólidos e manejo de águas pluviais.

Entretanto, segundo a FUNASA (2012), o PM SB deve estar em consonância com os Planos Diretores, com os objetivos e as diretrizes dos Planos Plurianuais (PPA), com os Planos de Recursos Hídricos, com os Planos de Resíduos Sólidos, com a legislação ambiental, com a legislação de saúde e de educação e devem ser compatíveis e integrados com todas as demais políticas públicas, planos e disciplinamentos do município relacionados ao gerenciamento do espaço urbano.

0 desafio em questão é como inserir os PMSBs no contexto do planejamento das políticas públicas, considerando as diferentes realidades e carência dos municípios da Amazônia, incluindo sua própria condição de construí-lo e implementá-lo?

Em suma, existem instrumentos de planejamento disponíveis para equacionar os problemas urbanos e municipais, mais não se consegue compreender a conectividade entre os instrumentos diante das especificidades quanto à escala de prioridades e a capacidade de implementação. Dessa forma, sem entrar no mérito dos regulamentos, prevalece o descrédito dos modelos operacionais e a falta de integração entre as políticas que lidam com os problemas urbanos, com a consequente precarização da gestão pública municipal.

Os instrumentos de ordenamento urbano, entretanto, tornam-se frágeis diante de fenômenos socioeconômicos não previsíveis. No caso do Amapá, a mineração e 0 comércio respondem por profundas mudanças do comportamento econômico e populacional do estado.

\section{DINÂMICA ECONÔMICA, CRESCIMENTO POPULACIONAL E CONCENTRAÇÃO UR- BANA}

A dinâmica econômica e demográfica do Amapá apresenta dois fenômenos muito bem identificados: a mineração industrial de manganês com o boom entre as décadas de 1950 a 1970 e a criação da área de livre comércio de Macapá-Santana na década de 1990.

A mineração industrial de manganês iniciada na década de 1950 foi o marco da dinâmica econômica e demográfica do Amapá. Primeiro grande empreendimento de mineração a se instalar na Amazônia, a exploração das jazidas de manganês da região de Serra do Navio, no Amapá, modificou a geopolítica do pós-guerra (LEAL, 1988) e inseriu a região no mapa dos conflitos que se perpetuam pós-exaustão diante de um boom de quase 50 anos de exploração mineral (CHAGAS, 2013). Nas décadas em que se deu a exploração de manganês, o Amapá passou de uma população de 37.477 habitantes em 1950 para 116.480 em 1970. 0 incremento populacional foi absorvido 
pela economia do manganês, facilidades públicas da condição de Território Federal e baixa densidade demográfica.

Entretanto, foi à criação da Zona de Livre Comércio de M acapá e Santana (ZLCM S), em 1991, responsável pelo forte fluxo migratório para o Amapá sem que o estado dispusesse do devido aparato público de atendimento aos serviços básicos. Os censos de 1991 e 2000, período da implantação da ZLCMS, demonstram que o Amapá registrou em uma década um crescimento populacional da ordem de 60,67\% (Tabela 1).

Tabela 1 - Crescimento populacional do Amapá 1991-2000

\begin{tabular}{c|c|c|c}
\hline \multirow{2}{*}{ Área } & \multicolumn{2}{|c|}{ População } & Taxa Média de Cresci- \\
& 1991 & 2000 & mento (\%) \\
\hline Amapá & 289.397 & 477.032 & 60,67 \\
\hline
\end{tabular}

Fonte: IBGE $(1991,2000)$.

0 crescimento populacional do Amapá se deu de forma concentrada, a ponto de 0 estado apresentar atualmente o maior índice de concentração urbana entre os estados da região Amazônica, atingindo 99,3\% em 2010 (Tabela 2).

Tabela 2 - Indicadores Urbanos do Amapá comparados com outros Estados da Amazônia

\begin{tabular}{l|c|c|c}
\hline \multicolumn{1}{c|}{ Estado } & População (hab.) & $\begin{array}{c}\text { População Urbana } \\
\text { (hab.) }\end{array}$ & $\begin{array}{c}\text { \% da População Ur- } \\
\text { bana }\end{array}$ \\
\hline Acre & 733.559 & 532.279 & 66,4 \\
\hline Amapá & 669.526 & 601.036 & 99,3 \\
\hline Amazonas & 2.812 .600 & 2.755 .490 & 79,1 \\
\hline Pará & 7.581 .051 & 5.191 .559 & 68,5 \\
\hline Rondônia & 1.562 .409 & 1.149 .180 & 73,6 \\
\hline Roraima & 450.479 & 344.859 & 76,6 \\
\hline Região Norte & 13.809 .624 & 10.574 .403 & 76,6 \\
\hline
\end{tabular}

Fonte: IBGE (2010).

A urbanização acelerada do Amapá, principalmente nas cidades de Macapá, Santana e Laranjal do Jari, tem pressionado a estrutura institucional pública, que não consegue acompanhar a demanda por serviços básicos, agravando as condições de vida da população. Um dos setores de maior impacto negativo é o saneamento (Tabela 3). 
Tabela 3 - Condição de Saneamento dos Municípios do Amapá

\begin{tabular}{l|c|c|c}
\hline \multicolumn{1}{c|}{ Município } & $\begin{array}{c}\text { Acesso Inadequado } \\
\text { ao Abastecimento de } \\
\text { Água (\%) }\end{array}$ & $\begin{array}{c}\text { Esgotamento Sanitá- } \\
\text { rio Inadequado }\end{array}$ & $\begin{array}{c}\text { Indisponibilidade de } \\
\text { Banheiro ou Sanitário }\end{array}$ \\
\hline Amapá & 13,0 & 83,0 & 13,0 \\
\hline Calçoene & 10,0 & 97,0 & 27,0 \\
\hline Cutias & 19,0 & 97,0 & 3,0 \\
\hline Ferreira Gomes & 3,0 & 96,0 & 6,0 \\
\hline Itaubal & 4,0 & 89,0 & 8,0 \\
\hline Laranjal do Jari & 20,0 & 99,0 & 8,0 \\
\hline Macapá & 46,0 & 68,0 & 6,0 \\
\hline Mazagão & 29,0 & 86,0 & 12,0 \\
\hline Oiapoque & 10,0 & 94,0 & 32,0 \\
\hline Pedra Branca & 29,0 & 96,0 & 5,0 \\
\hline Porto Grande & 13,0 & 94,0 & 9,0 \\
\hline Pracuúba & 3,0 & 90,0 & 4,0 \\
\hline Santana & 40,0 & 80,0 & 9,0 \\
\hline Serra do Navio & 7,0 & 52,0 & 26,0 \\
\hline Tartarugalzinho & 21,0 & 99,0 & 17,0 \\
\hline Vitória do Jari & 37,0 & 99,0 & 12,6 \\
\hline Média do Estado & 19,0 & 88,7 & \\
\hline Fonte: & & & \\
\hline
\end{tabular}

Fonte: IBGE (2000), organizado por Rocha (2002).

A Pesquisa Nacional de Saneamento Básico realizada em 2008 pelo IBGE mostra que as condições de saneamento nos municípios do Amapá continuam críticas, assim como na maioria dos estados da Amazônia. O Amapá não dispõe de abastecimento de água para $59,4 \%$ de seus domicílios e somente $3,5 \%$ são atendidos com rede geral coletora de esgoto, enquanto a média nacional é $21,4 \%$ e $44,0 \%$, respectivamente.

Macapá, a capital do Amapá, concentra $59,5 \%$ da população do estado (IBGE, 2014). A cidade está situada no nível do mar e apresenta vários trechos de relevo negativo invadidos pelas marés do rio Amazonas. Essas áreas são conhecidas regionalmente como "ressacas" e, pela fragilidade das políticas públicas, vem sendo ocupadas pela população de baixa renda, transformando-se em verdadeiras "favelas das águas". Essa condição coloca Macapá entre as cidades com os piores índices de saneamento do País, conforme pesquisa realizada pelo Instituto Trata Brasil e divulgada pela Revista Época em 2015 (Figura 1). 
Figura 1 - Ranking das cidades com piores índices de saneamento básico

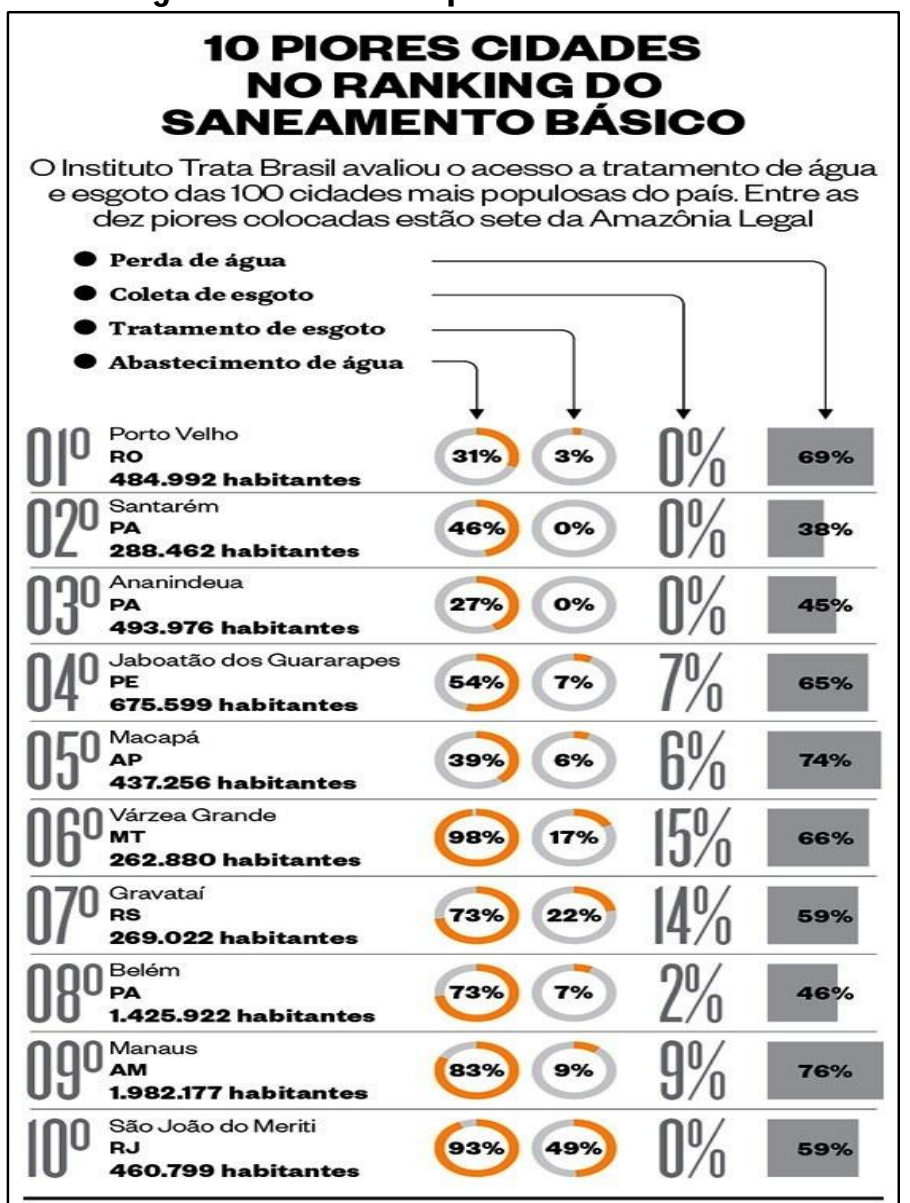

Fonte: Revista Época (2015).

Embora cerca de $70 \%$ da população amazônica viva em núcleos urbanos, a urbanização é negligenciada nos estudos sobre a região, tese sustentada por Becker (2013, p. 11) e de ampla perspectiva de análise acadêmica, principalmente quando integrada ao tema da preservação da floresta.

\section{PRESERVAÇÃO DA FLORESTA E DAS PESSOAS}

A relação dialética cidade-floresta é o alicerce das análises sobre as mudanças estruturais e dinâmicas socioeconômicas, ambientais e políticas na Amazônia (BECKER, $2001,2004,2013)$. Becker parte do pressuposto que a apropriação direta dos territórios e recursos na Amazônia está associada à nova geopolítica mundial e que tanto as cidades como a floresta são impactadas pela dinâmica do mercado. A articulação entre o complexo urbano e o complexo verde é determinante para o desenvolvimento da Amazônia, conclui Becker (2013).

0 papel da urbanização, ainda que negligenciado pelas políticas públicas, torna-se o cerne para a construção de um projeto regional para a Amazônia, onde o maior desafio está em conciliar o desenvolvimento com a preservação das "florestas em pé", 
valorizando os serviços ecossistêmicos e garantindo seu manejo sustentável (BECKER, 2013).

O Amapá, estado que detém $56 \%$ do seu território em unidades de conservação, a taxa de crescimento populacional e de concentração urbana atinge os maiores índices entre as estados da Amazônia, pressionando as políticas públicas que não conseguem atender às demandas da população por serviços básicos.

Quando se avalia a ausência de saneamento das cidades do Amapá, a maioria nucleando unidades de conservação, percebe-se um antagonismo socioambiental diante do status de região de floresta preservada e precárias condições de vida urbana.

0 desenvolvimento da economia da floresta como estratégia de dinamizar e integrar as cidades é valida, mas ainda distante de uma efetiva política que possa sanear as cidades como forma de preserva a floresta, incluindo a própria possibilidade de interação entre as pessoas e a natureza.

\section{CONCLUSÃO}

Não se tem uma teoria que possa conectar a questão urbana da Amazônia a preservação da floresta. Os vínculos são mais éticos, a considerar que o status de abrigar unidades de conservação implica na busca de instrumentos de gestão ambiental e urbana que possam equacionar problemas comuns.

O Zoneamento, o Plano Diretor e os recentes PM SB constituem iniciativas de ordenamento territorial das cidades que urge pelo pragmatismo diante dos problemas urbanos acumulados.

O saneamento básico das cidades do Amapá, sobretudo da capital, Macapá, tem forte apelo para tornar mais atrativo à condição de porta de entrada do estado mais preservado do Brasil.

\section{REFERÊNCIAS}

BECKER, Bertha. A Especificidade do Urbano na Amazônia: Desafios para Políticas Públicas Consequentes. Cadernos NAPIAm, n. 02. Brasília: M M A/SCA/PPG7. 1999. BECKER, Bertha. A urbe amazônida: a floresta e a cidade. Rio de Janeiro: Garamond Universitária. 2013.

CHAGAS, Marco Antonio. Amapá: a mineração e o discurso da sustentabilidade - de Augusto Antunes a Eike Batista. Rio de Janeiro: Editora Garamond. 2013.

FUNASA. Termo de Referência para Elaboração de Planos Municipais de Saneamento Básico. Fundação Nacional da Saúde. Brasília. 2012.

IBGE. Pesquisa Nacional por Amostra de Domicílios Contínua 2014.

LEAL, Aluízio Lins. Amazônia: aspecto político da questão mineral. Dissertação (mestrado em Planejamento do Desenvolvimento). Belém: NAEA-UFPA. 1988. 
REVISTA ÉPOCA. Cidades da Amazônia estão na lanterna no ranking do saneamento básico. Disponível em: বhttp://epoca.globo.com/colunas-e-blogs/blog-doplaneta/amazonia/noticia/2015/05/ cidades-da-amazonia-estao-na-lanterna-noranking-do-saneamento-basico.html>. Acesso em: 03 ago. 2015.

SAWYER, D. R. e SCHUWARTZM AN, S. Uma agenda urbana para a Amazônia e o Programa Piloto. In: Smeraldi, R. et al. Políticas Públicas para a Amazônia - rumos, tendências e propostas. Brasília, GTA e Amigos da Terra. Cap.6, p. 47-52. 1997.

TOSTES, José Alberto. Planos Diretores no Estado do Amapá. Macapá: J.A. Tostes, 2006.

TOSTES, José Alberto. Do fazejamento ao arranjamento nas cidades do Amapá. Disponível em: ঝttp://josealbertostes.blogspot.com.br/2014/01/do-fazejamento-aoarranjamento-nas.html>. Acesso em: 29 jul. 2015.

TOSTES, José Alberto. As fragilidades impostas pelo "Fazejamento urbano". Disponível em: http://josealbertostes.blogspot.com.br/2015/03/as-fragilidades-impostaspelo.html. Acesso em: 29 jul. 2015

VILAÇA, Flávio. As llusões do Plano Diretor. Disponível em: ঝttp://www.flaviovillaca. arq.br/pdf/ilusao_pd.pdf>. Acesso em: 22 jul. 2015.

Artigo recebido em 14 de julho de 2016.

Aprovado em 18 de julho de 2016. 